\title{
Revisão Sistemática sobre o perfil de competências do gestor desportivo
}

\author{
Bárbara Andreia Joaquim* \\ Paula Maria Batista ${ }^{* *}$ \\ Maria José Carvalho ${ }^{* * *}$
}

\begin{abstract}
Resumo: Este é um estudo de revisão sistemática da literatura relativa às competências e funções do gestor desportivo. Efetuou-se a pesquisa em bases de dados electrónicas no período de 1980-2009, e em dissertações de mestrado e doutoramento de Universidades Públicas Portuguesas. As palavras-chave utilizadas foram: "sport manager", "sport directors", "sport manager and organization", "competency and sport manager", "sport director and organizational", "responsibilities and sport managers". Resultaram 30 estudos, 15 artigos peer review e 15 dissertações. As competências e as funções mais valorizadas foram: planeamento, gestão de recursos, liderança, marketing, controlo e coordenação de equipas, sendo o planeamento transversal aos diversos estudos.

Palavras-chave: Gerência. Esportes: organização e administração. Literatura de Revisão como Assunto
\end{abstract}

\section{INTRODUÇÃo}

A constante evolução que ocorre no sector desportivo e o interesse crescente pelo e no desporto dos vários consumidores e profissionais desportivos, incrementou a investigação e o debate em torno do fenómeno desportivo. A área da gestão do desporto, designadamente as competências e funções dos profissionais que promovem e organizam os mais diversificados contextos do desporto, também não escapou a este investimento de pesquisa.

* Prof. ${ }^{a}$ de Educação Física Mestra em Gestão Desportiva. Gabinete de Gestão Desportiva da Faculdade de Desporto da Universidade do Porto. Porto, Portugal. E-mail: barbarajo23@gmail.com. ** Professora Auxiliar. Doutora em Ciências do Desporto. Gabinete de Pedagogia do Desporto. Faculdade de Desporto da Universidade do Porto. Porto, Portugal. Membro associado do CIFI2D. E-mail: paulabatista@fade.up.pt

*** Professora Auxiliar. Doutora Ciências do Desporto. Gabinete de Gestão Desportiva Faculdade de Desporto da Universidade do Porto. Porto, Portugal. Membro efectivo do CIFI2D.

E-mail: mjc@fade.up.pt 
É inquestionável que os profissionais que laboram no domínio da gestão desportiva têm de se preocupar com a organização e a coordenação de um conjunto de atividades, que se prendem com diferentes âmbitos intervenção, desde a gestão de instalações, à organização de eventos, à gestão de recursos humanos, às relações públicas e laborais, à legislação desportiva, até à execução de tarefas financeiras (Chelladurai, 1995). Assim, os gestores desportivos, atendendo à dimensão e âmbito da respectiva atividade, assim como a tipologia da instituição, assumem diferentes funções, posições e níveis hierárquicos dentro de uma determinada organização.

O exercício de funções no domínio da gestão desportiva tem sido protagonizado por profissionais cuja designação tem sido diferenciada, nomeadamente diretor técnico, administrador, técnico e dirigente desportivo, não obstante as atividades desempenhadas serem similares.

Em Portugal, os estudos desenvolvidos acerca do gestor desportivo têm incidido essencialmente na identificação do que o gestor deve fazer (COSTA, 2002; DuARTE, 2004), descurando, de certo modo, as competências e funções que estes profissionais desempenham nas organizações desportivas.

Deste modo, e atendendo à modernização das sociedades, à existência e sucessiva criação de múltiplas organizações desportivas, à diversidade de designações e funções desempenhadas pelos gestores desportivos, bem como a insuficiente clarificação das competências requeridas ao exercício da função, assume-se como relevante investigar o perfil de competências e funções atribuídas pela literatura.

Assim sendo, trata-se de um estudo de revisão sistemática cujo propósito é aprofundar os conhecimentos acerca das funções e competências dos gestores desportivos, tanto a nível nacional como internacional. A pesquisa está estruturada em dois pontos temáticos, designadamente, (1) estudos empíricos internacionais e produção académica em Portugal acerca das competências e funções dos gestores desportivos; (2) competências e funções dos gestores desportivos nas variantes terminológicas de administradores, diretores e dirigentes desportivos igualmente a nível internacional e em Portugal.

Movimesto, Porto Alegre, v. 17, n. 01, p. 255-279, janeiro/março de 2011. 


\section{Metodologia}

Pelas características da revisão sistemática a operacionalização do estudo é de natureza qualitativa. Os estudos foram recolhidos de duas fontes diferenciadas: bases de dados eletrónicas (EBSCO, Business Source Complete e Digital Dissertations \& Theses), e dissertações de mestrado e doutoramento. As palavras-chave utilizadas nas pesquisas foram: "sport manager", "sport directors", "sport manager and organization", "competency and sport manager", "sport director and organizational", "responsibilities and sport managers".

Inicialmente, todos os estudos que apresentavam no título uma das palavras-chave foram selecionados para leitura. Contudo, das 65 produções científicas listadas, somente 30 atendiam aos critérios de inclusão: estudos empíricos sobre o perfil de competências e funções dos gestores desportivos realizados internacionalmente e em Portugal, quer fossem dissertações académicas quer fossem artigos peer review. Os critérios de exclusão foram: artigos de revisão e artigos de opinião de especialistas. Os estudos científicos selecionados para esta revisão compreendem o período de 1980 a 2009.

As dissertações académicas internacionais de mestrado e de doutoramento foram consultadas na base de dados Digital Dissertations \& Theses, e as dissertações académicas portuguesas foram consultadas em três instituições de ensino superior público, a Faculdade de Desporto da Universidade do Porto, a Faculdade de Motricidade Humana da Universidade Técnica de Lisboa e a Universidade de Trás-os-Montes e Alto Douro. Os artigos peer review foram consultados nas restantes bases de dados supracitadas.

As 30 produções científicas selecionadas compreendem 24 estudos internacionais, 15 artigos de revistas peer review, 9 dissertações académicas (Quadro 1) e 6 publicações portuguesas, correspondendo a dissertações académicas (Quadro 2).

$\mathrm{Na}$ análise da informação utilizaram-se procedimentos de análise de conteúdo, sendo que as categorias foram estabelecidas a priori: temática, contextos profissionais, instrumentos (coleta de dados), amostra e principais resultados. Complementarmente

Movimento, Porto Alegre, v. 17, n. 01, p. 255-279, janeiro/março de 2011. 
procedeu-se ainda a uma sistematização do local (país) em que os estudos foram efectuados, bem como a uma panorâmica das temáticas em termos cronológicos. A categorização foi efectuada com recurso ao software de análise qualitativa, o NVivo 7.

\subsection{COMPETÊNCIAS E FUNÇÕES DE GESTORES DESPORTIVOS}

Apresenta-se de seguida uma sinopse dos estudos empíricos internacionais respeitantes às competências e funções dos gestores desportivos e ulteriormente os estudos efetuados em Portugal sobre a mesma temática.

\subsubsection{PANORÂMICA dos Estudos EmpíRICOS INTERNACIONAIS}

A nível internacional, as investigações reportam-se a diferentes profissionais com funções na área de gestão do desporto, designadamente, gestores, diretores, e administradores desportivos, sendo que os contextos profissionais sobre os quais incidiram as pesquisas também são distintos, conforme ilustra a evolução cronológica apresentada no Quadro 1.

Movimento, Porto Alegre, v. 17, n. 01, p. 255-279, janeiro/março de 2011. 


\begin{tabular}{|c|c|c|c|c|c|}
\hline 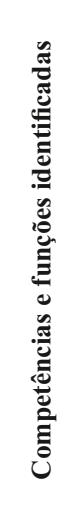 & 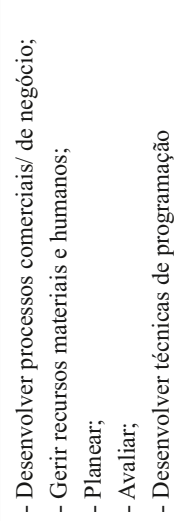 & 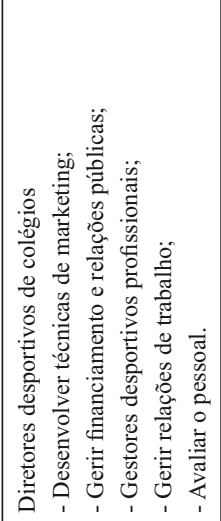 & 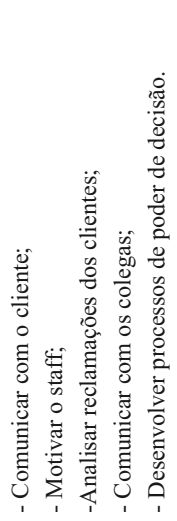 & 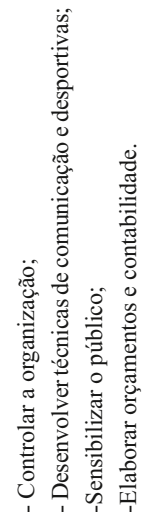 & 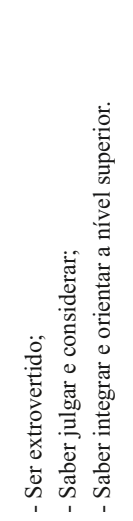 \\
\hline 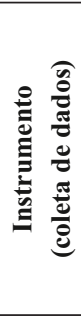 & 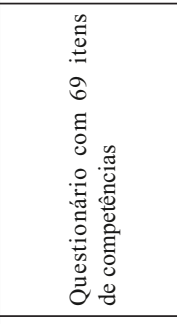 & 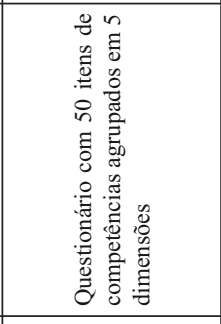 & 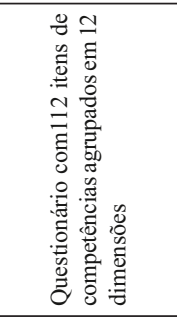 & 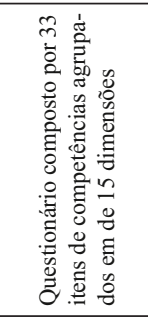 & 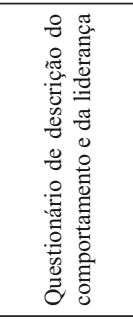 \\
\hline 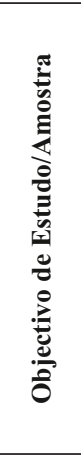 & 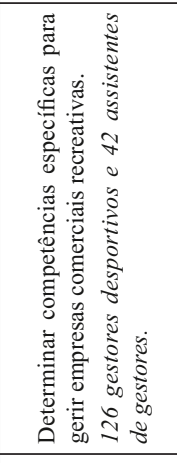 & 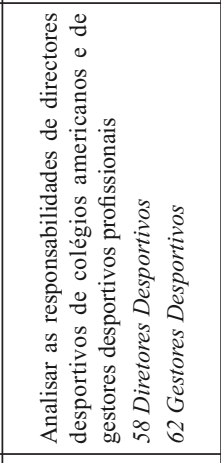 & 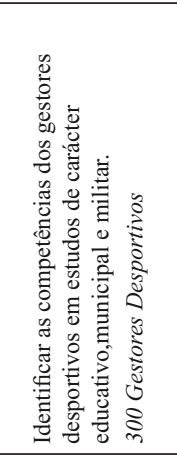 & 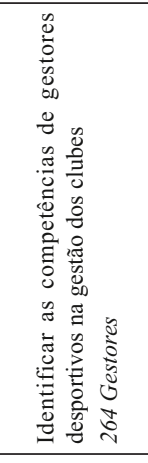 & 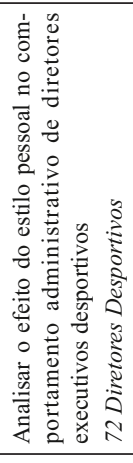 \\
\hline$\stackrel{\varrho}{\ell}$ & $\begin{array}{l}\text { 志 } \\
\stackrel{2}{2}\end{array}$ & $\stackrel{\infty}{\sigma}$ & $\stackrel{\infty}{\stackrel{\infty}{\sigma}}$ & $\stackrel{\circ}{\stackrel{\circ}{\sigma}}$ & $\stackrel{\infty}{\stackrel{\infty}{\sim}}$ \\
\hline 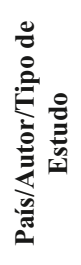 & 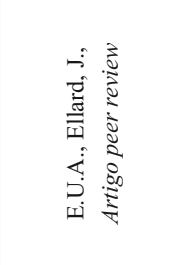 & 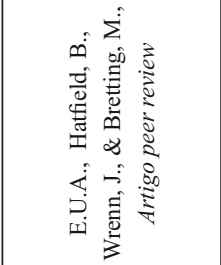 & 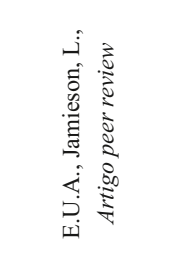 & 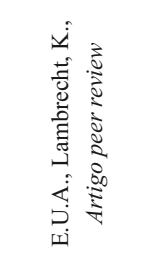 & 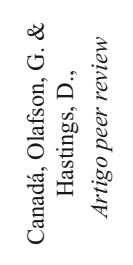 \\
\hline
\end{tabular}

Movimento, Porto Alegre, v. 17, n. 01, p. 255-279, janeiro/março de 2011. 


\begin{tabular}{|c|c|c|c|c|}
\hline 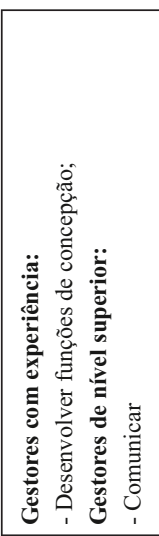 & 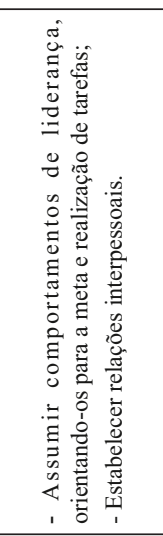 & 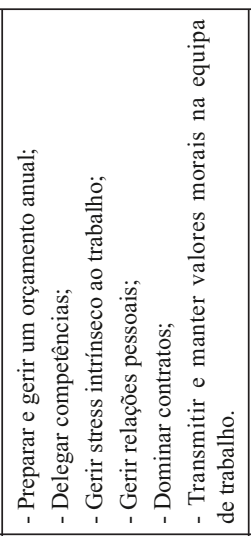 & 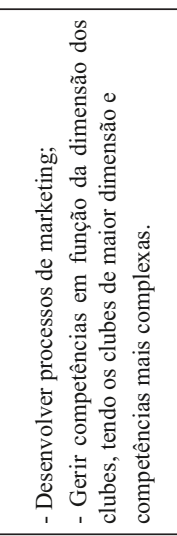 & 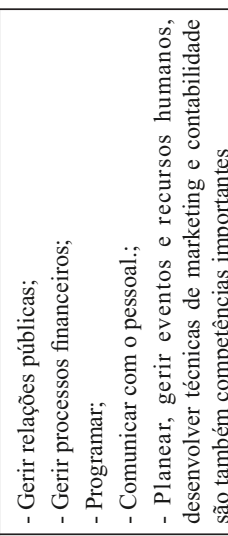 \\
\hline 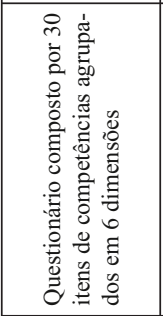 & 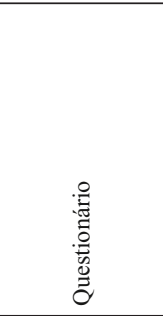 & 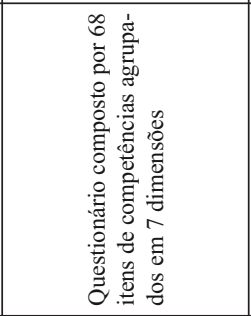 & 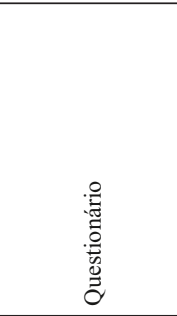 & 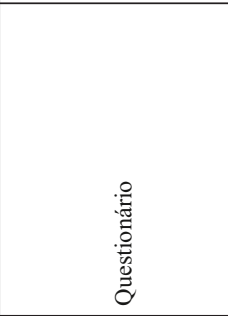 \\
\hline 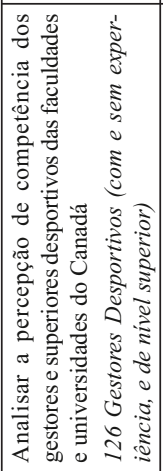 & 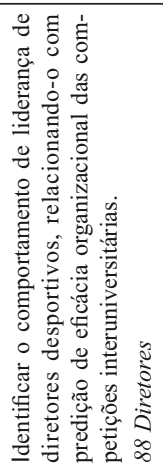 & 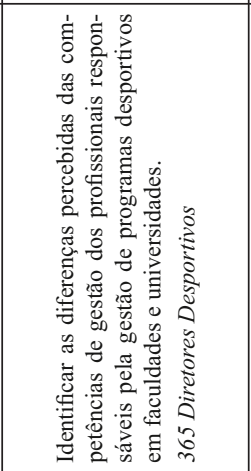 & 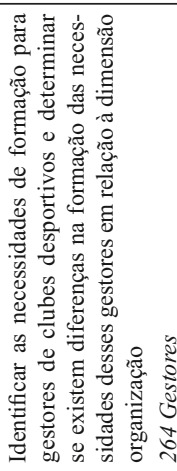 & 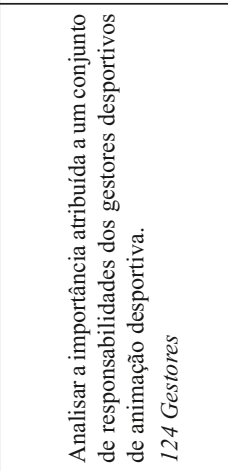 \\
\hline $\begin{array}{l}\infty \\
\stackrel{\infty}{\circ}\end{array}$ & ঃ & \& & $\bar{\sigma}$ & $\bar{\sigma}$ \\
\hline 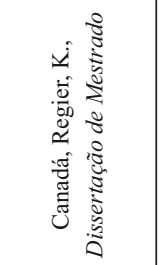 & 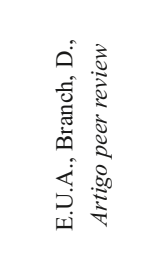 & 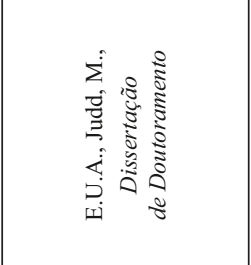 & 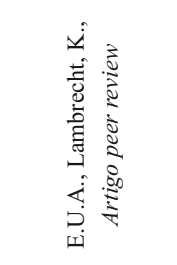 & 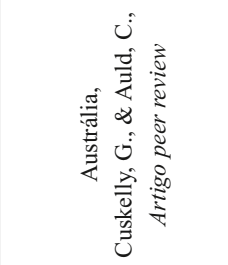 \\
\hline
\end{tabular}

Movimento, Porto Alegre, v. 17, n. 01, p. 255-279, janeiro/março de 2011. 


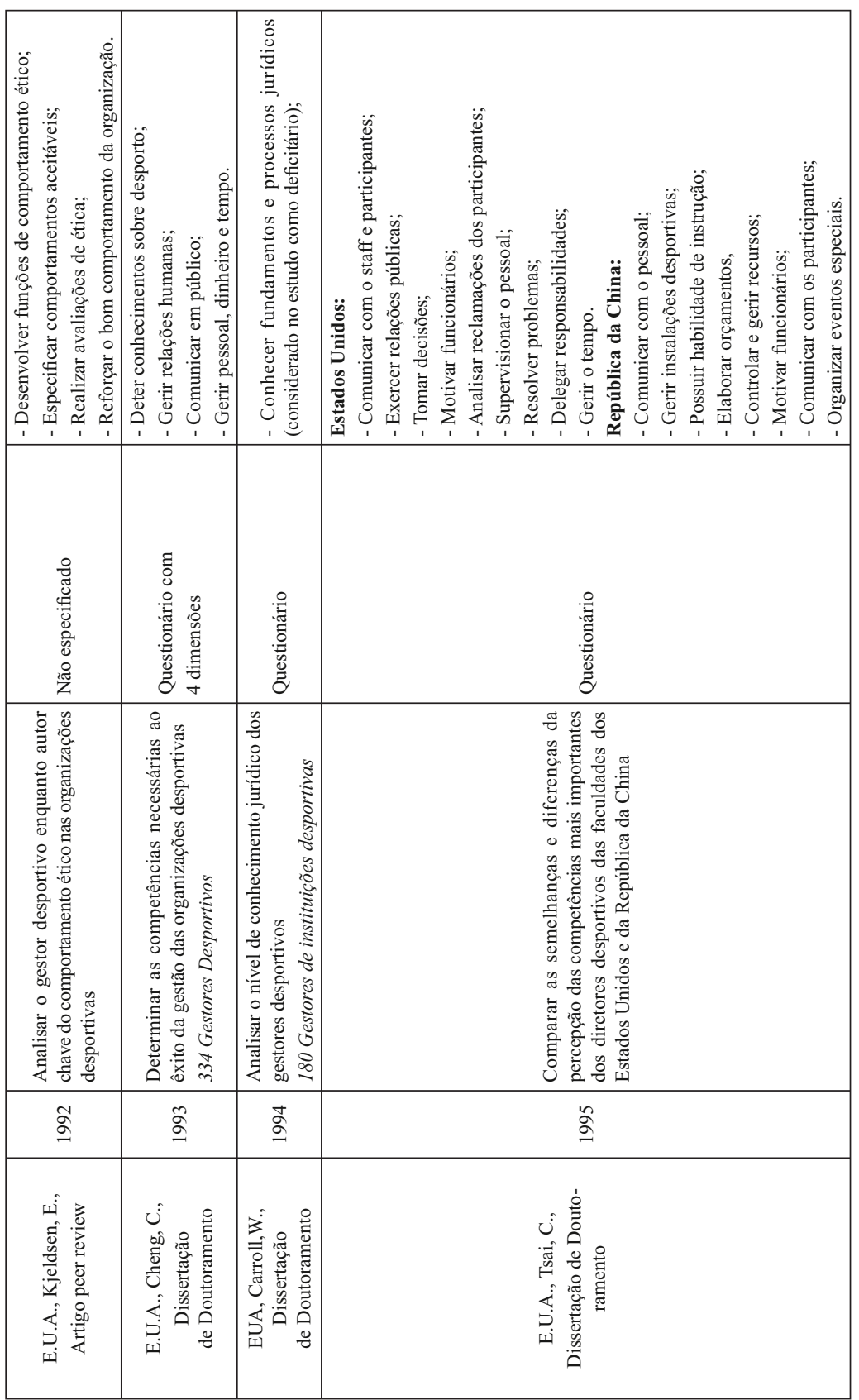

Wovimento, Porto Alegre, v. 17, n. 01, p. 255-279, janeiro/março de 2011. 


\begin{tabular}{|c|c|c|}
\hline 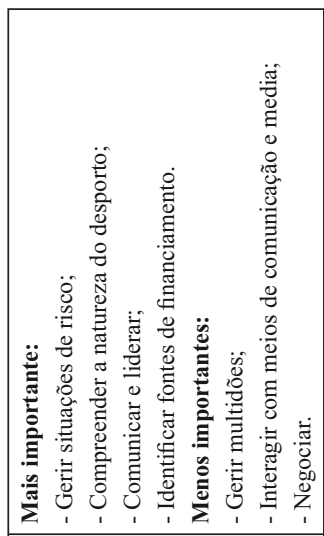 & 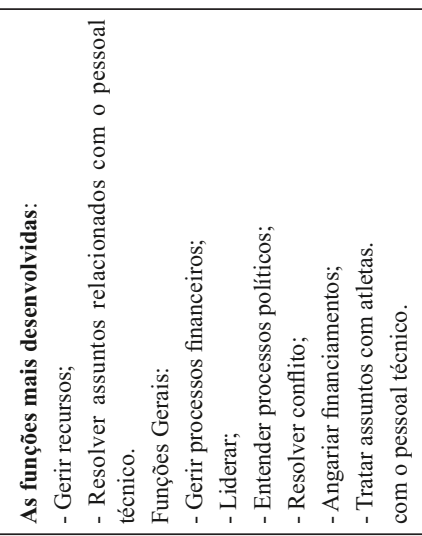 & 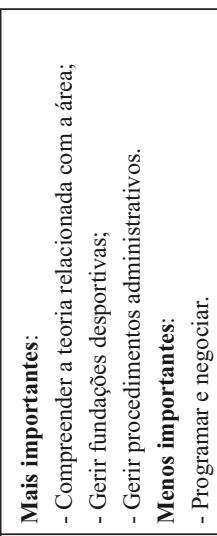 \\
\hline 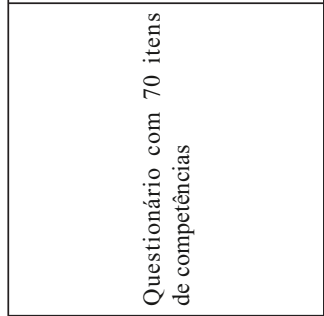 & & 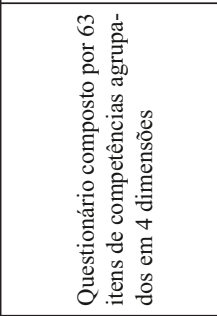 \\
\hline 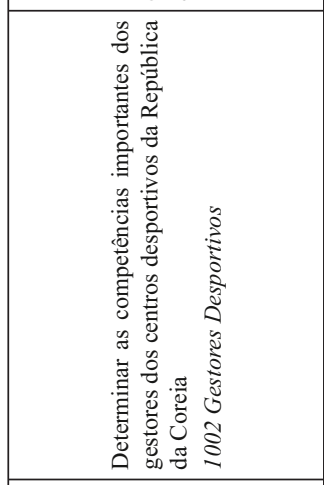 & 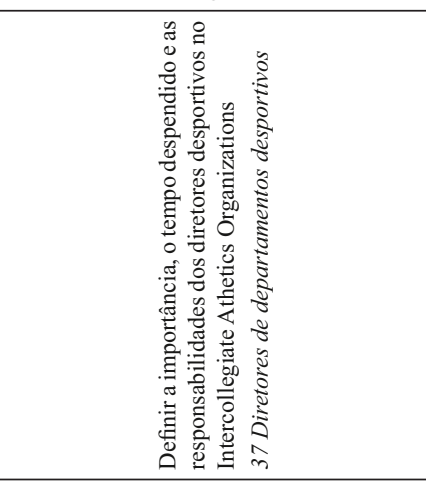 & 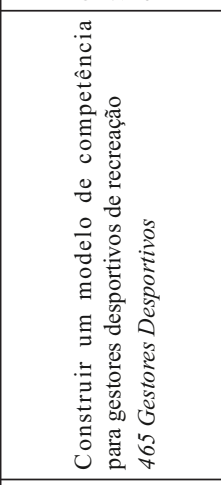 \\
\hline$\hat{\sigma}$ & ڤे & 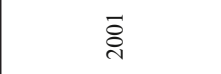 \\
\hline 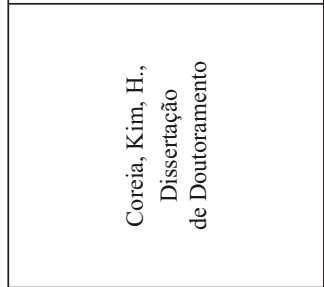 & 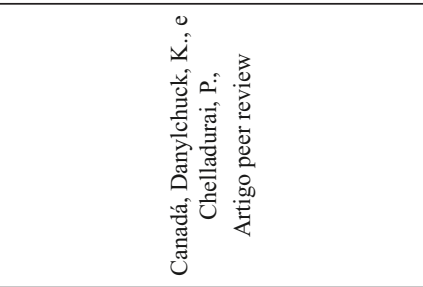 & 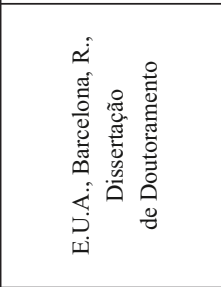 \\
\hline
\end{tabular}

Novimento, Porto Alegre, v. 17, n. 01, p. 255-279, janeiro/março de 2011. 


\begin{tabular}{|c|c|c|c|c|}
\hline 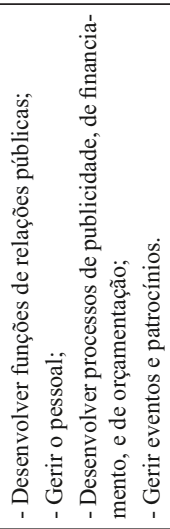 & 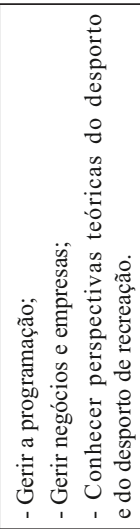 & 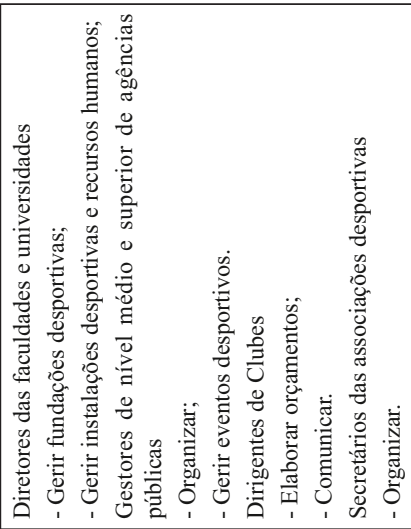 & 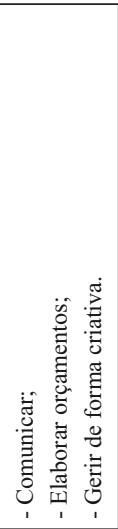 & 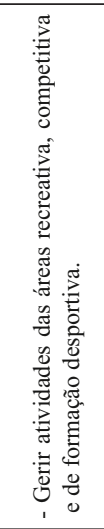 \\
\hline 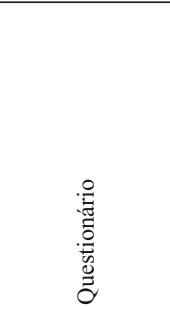 & 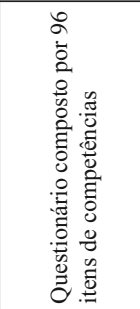 & 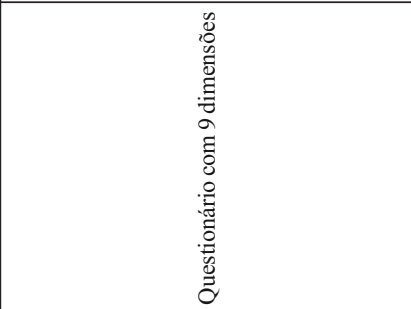 & 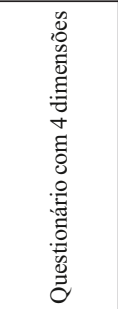 & 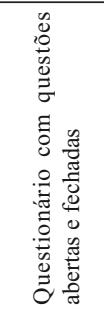 \\
\hline 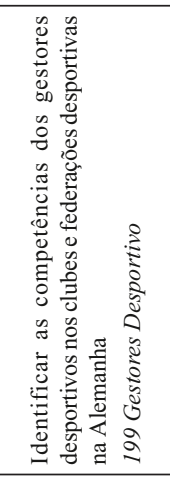 & 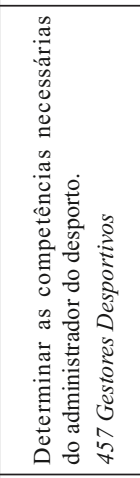 & 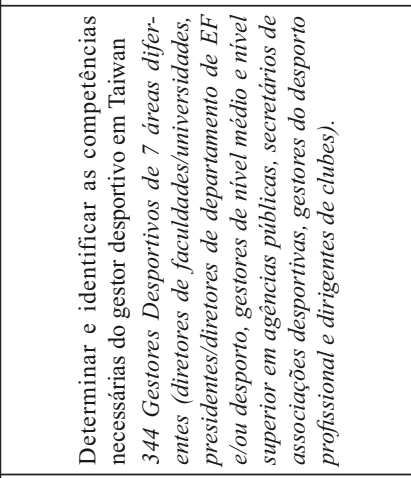 & 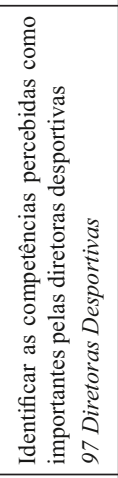 & 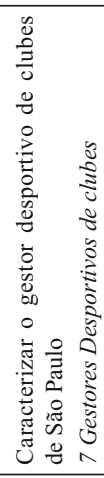 \\
\hline ڤ్రి & 总 & 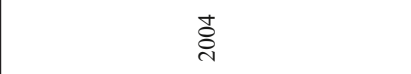 & 总 & : \\
\hline 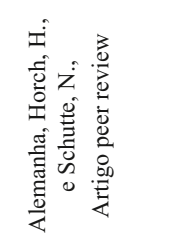 & 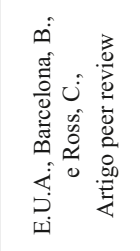 & 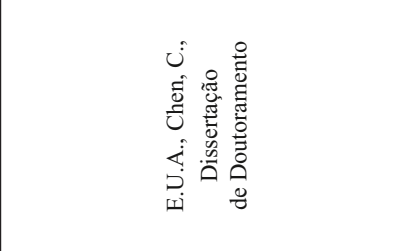 & 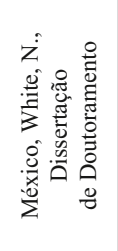 & 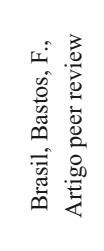 \\
\hline
\end{tabular}

Wovimento, Porto Alegre, v. 17, n. 01, p. 255-279, janeiro/março de 2011. 


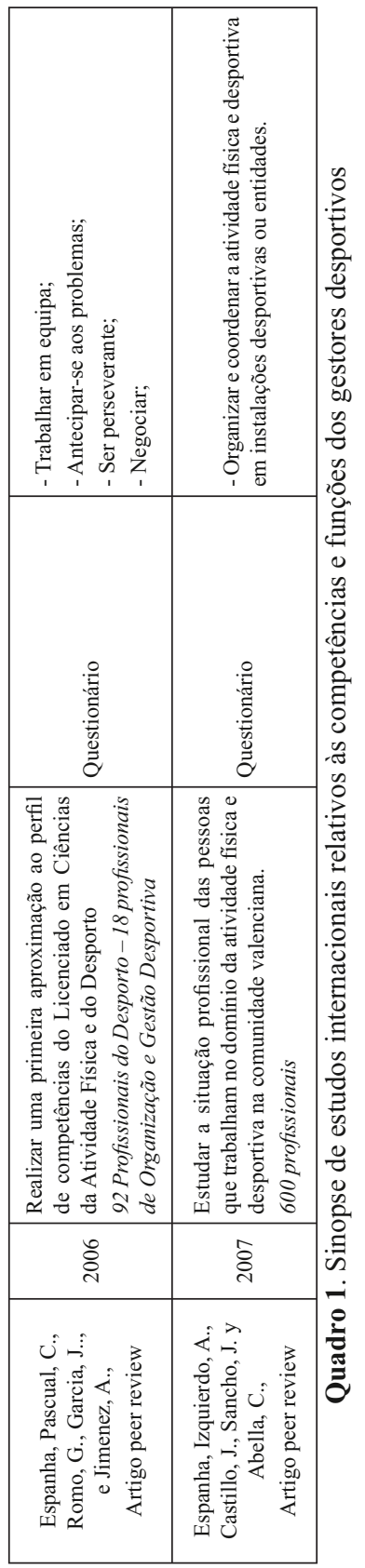

Wovimento, Porto Alegre, v. 17, n. 01, p. 255-279, janeiro/março de 2011. 
Como se pode constatar no Quadro 1, os estudos internacionais ocorreram em diferentes contextos profissionais da gestão desportiva, designadamente, ao nível educativo (colégios e universidades), militar, municipal, comercial (empresas comerciais recreacionais) e associativo (clubes e federações desportivas).

O instrumento de investigação utilizado na generalidade destes estudos foi o questionário. As amostras utilizadas nas investigações internacionais evidenciam características diversas, tanto no número como na tipologia de profissionais de gestão de desporto estudados. A maioria dos estudos possui uma amostra homogénea materializada em gestores desportivos (JAMIESON, 1987; LAMBRECHT, 1987; REgIER, 1988; Lambrecht, 1991; Cuskelly; Auld, 1991; Cheng, 1993; Carroll, 1994; Kim, 1997; Barcelona, 2001; Horch; Schutte, 2003; Barcelona; Ross, 2004; Bastos, 2006; Pascual; Romo; Garcia; JiMENEZ, 2006), em diretores desportivos (Olafson; Hastings, 1988; Branch, 1990; Judd, 1990; Danylchuck; Chelladurai, 1999; White, 2004), e administradores desportivos (FARMER, 1989). Contudo, existem também estudos com amostras heterogéneas, designadamente os trabalhos de Hatfield, Wrenn e Bretting (1987) e de Chen (2004), que integram simultaneamente diretores e gestores desportivos. No que concerne à dimensão da amostra, o estudo académico de Kim (1997) é aquele que apresenta a amostra mais numerosa (1002 gestores desportivos), seguindo-se a investigação de Izquierdo, Castilho, Sancho e Abella (2007), com uma amostra de 600 profissionais. Em contrapartida, a amostra mais reduzida compreende somente 7 gestores desportivos de clubes (BASTOS, 2006).

Destaque-se, a exceção do continente africano e a supremacia de investigações na América do Norte, designadamente no Canadá e nos E.U.A., justificando-se esta última pelo interesse demonstrado na gestão dos negócios no âmbito do desporto, essencialmente ao nível das ligas profissionais, e do sistema de competição inter-colégios e universidades.

Ao analisar-se a evolução cronológica dos estudos, constata-se um interesse pela temática nas últimas três décadas, mas com um ligeiro incremento na década de 90.

Movimento, Porto Alegre, v. 17, n. 01, p. 255-279, janeiro/março de 2011. 
Os primeiros estudos detectados nas bases de dados referenciadas, reportam-se à década de 80, sendo que Ellard (1984) realça no seu estudo as competências de gestão de recursos materiais e humanos, assim como os processos comerciais como necessários à gestão de empresas comerciais. Desta forma o autor advoga que a gestão e a rentabilização dos recursos que têm à disposição é indispensável para a eficiência e eficácia da organização de modo a alcançar os respectivos objectivos.

Ulteriormente, Hatfield, Wrenn e Breting (1987), evidenciaram o gestor desportivo como um "pivot", ou seja, como um elemento de ligação e de interface que se encontra em constante relação com pessoas na sua organização (superiores hierárquicos, subordinados, treinadores e jogadores) e exteriores a esta. Daí que as relações de trabalho, nomeadamente interagir com jogadores, avaliar os recursos humanos e negociar contratos, surgem como competências fulcrais para um gestor desportivo envolvido na gestão do desporto, neste caso em colégios americanos.

Os estudos sucederam-se especificando contextos particulares onde os gestores desportivos exerciam as suas funções e para as quais eram requeridas competências específicas consoante o âmbito profissional onde atuavam. Neste sentido, Jamieson (1987) procurou apurar que competências diferenciavam os gestores desportivos em diferentes contextos, nomeadamente no educativo, no municipal e no militar, tendo encontrado um perfil de competências semelhante independentemente do contexto em causa. Em contraponto, quando comparadas as competências mais valorizadas pelos gestores de associações regionais e locais e os das organizações comerciais (Cuskelly; Auld, 1991), foram mais valorizadas pelos primeiros as competências financeiras e legais, e pelos segundos as competências relacionadas com o exercício e com a saúde. Já Chen (2004) evidenciou que os gestores de nível médio e superior de agências públicas, os secretários das associações desportivas e os diretores das faculdades e universidades consideraram a competência "gerir" como uma das mais importantes. Tendo sido a elaboração de orçamentos e a comunicação as competências mais valorizadas pelos dirigentes de clubes.

Movimento, Porto Alegre, v. 17, n. 01, p. 255-279, janeiro/março de 2011. 
A gestão em contexto associativo, com especial enfoque nos clubes desportivos, foi objecto de abordagem por Lambrecht (1987 e 1991), Horch e Schutte (2003) e Chen (2004). O controlo da organização, as técnicas de comunicação e desportivas, a publicidade, o financiamento, a sensibilização do público (relações públicas), o patrocínio, a gestão de eventos, a elaboração de orçamentos, de contabilidade, e o marketing são as competências mais valorizadas. Lambrecht (1991) refere ainda que as competências de gestão variam em complexidade, sendo esta proporcional à dimensão dos clubes.

Focando, de seguida, a atenção em competências que emergiram e se tornaram constantes nos diversos estudos analisados, é de mencionar as competências relacionadas com as técnicas de marketing, como está patente nas pesquisas de Hatfield, Wrenn e Bretting (1987), Lambrecht (1991) e Cuskelly e Auld (1991). Com o aumento da concorrência (inovação ao nível dos serviços e produtos) o marketing assumiu-se como uma função fulcral a desempenhar pelos gestores desportivos de modo a atender às necessidades e desejos da população e assim captá-la e fidelizá-la para a prática de desporto.

Constatou-se, igualmente, que possuir conhecimento especializado (da natureza do desporto e de algumas áreas intrínsecas a este fenómeno) é uma competência que emerge a partir da década de 90 (Cheng, 1993; Carroll, 1994; Kim, 1997; Barcelona, 2001; BarceLONA; Ross, 2004). O mesmo se passou com a capacidade de comunicar com diferentes populações-alvo e em distintos contextos, considerada imprescindível para manter a harmonia e o entendimento no seio de uma organização, como é evidenciado nos estudos de Jamieson (1987), Lambrecht (1987), Regier (1988), Farmer (1989), Cuskelly (1991), Cheng (1993), Tsai (1995), Kim (1997), Chen (2004) e White (2004).

Ulteriormente, as pesquisas centradas no comportamento do gestor desportivo relevaram a liderança, a motivação e a ética como competências nucleares para o desempenho das suas funções em distintas equipas de trabalho (Olafson; Hastings, 1988; Branch, 1990; KJeldsen, 1992; Tsai, 1995; E Danylchuck; Chelladurai, 1999).

Estudos mais recentes (Chen, 2004; Bastos, 2006; Pascual, Romo, Garcia; Jimenez, 2006; IzQuierdo; Castillo; Sancho; Abella,

Movimento, Porto Alegre, v. 17, n. 01, p. 255-279, janeiro/março de 2011. 
2007) revelam que as competências mais valorizadas pelos gestores desportivos a capacidade de trabalhar em equipa e de antecipação dos problemas, a perseverança, a capacidade de negociação e a capacidade de gerir instalações e eventos desportivos.

Em suma, os contextos profissionais, as especialidades, os âmbitos e níveis de intervenção dos gestores desportivos devem ser equacionados aquando da identificação do perfil de competências que lhes está adstrito. Acresce que, distintas políticas, propósitos e objectivos das organizações, departamentos, secções e níveis hierárquicos reclamam competências específicas, assim como importância e valorização diferenciada. Constatou-se que as competências básicas, designadamente, o planeamento, a organização, a execução, o controlo, a comunicação e a tomada de decisão são comuns e inerentes aos profissionais de gestão desportiva.

\subsubsection{Produção Académica em Portugal}

A produção académica em Portugal tem tido o seu foco em torno de diferentes profissionais com funções na área de gestão do desporto. Constata-se que tais profissionais são designados de forma diferenciada, nomeadamente, gestores, diretores técnicos e dirigentes desportivos, aos quais correspondem contextos profissionais distintos, como se pode observar no Quadro 2.

Movimento, Porto Alegre, v. 17, n. 01, p. 255-279, janeiro/março de 2011. 


\begin{tabular}{|c|c|c|c|c|}
\hline 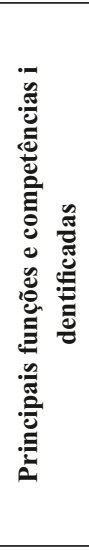 & 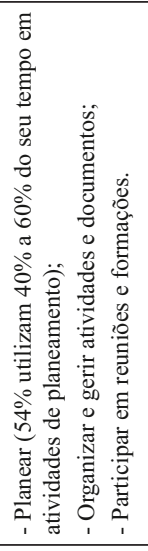 & 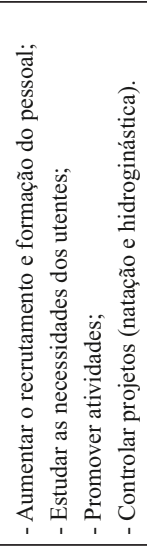 & 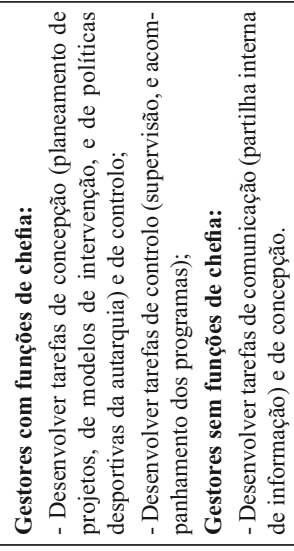 & 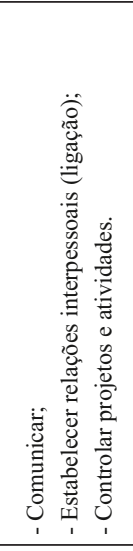 \\
\hline 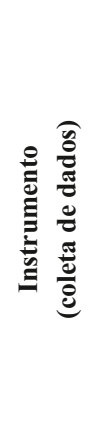 & 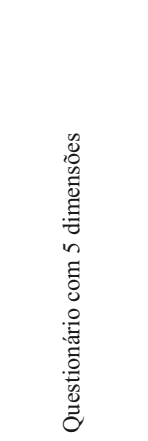 & 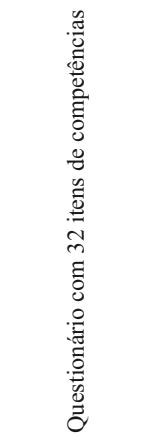 & 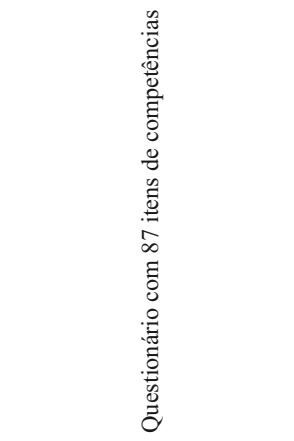 & 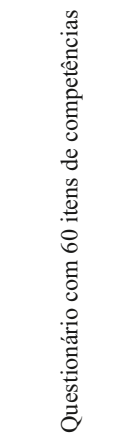 \\
\hline 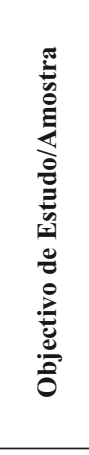 & 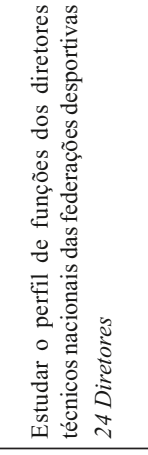 & 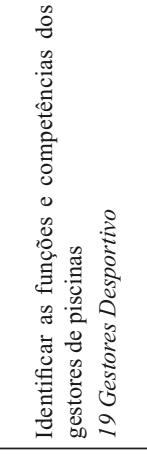 & 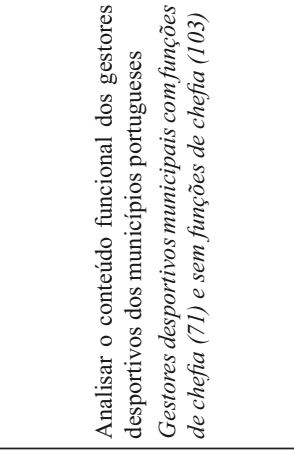 & 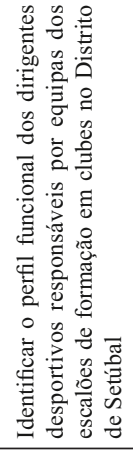 \\
\hline 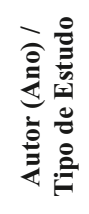 & 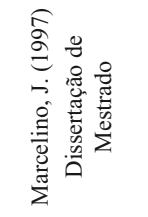 & 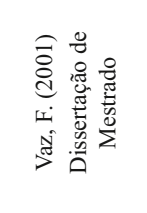 & 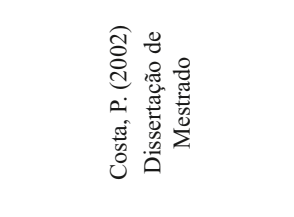 & 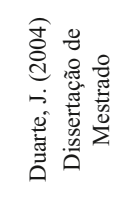 \\
\hline
\end{tabular}

Movimento, Porto Alegre, v. 17, n. 01, p. 255-279, janeiro/março de 2011. 


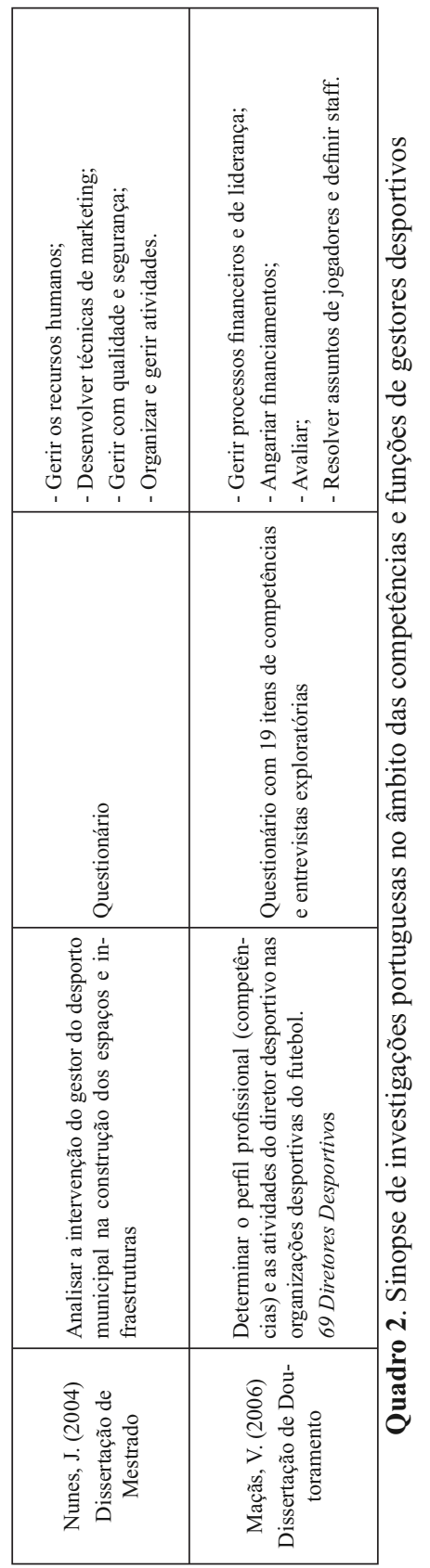

Wovimento, Porto Alegre, v. 17, n. 01, p. 255-279, janeiro/março de 2011. 
A leitura do Quadro 2 coloca em evidência que as investigações portuguesas acerca da temática em causa datam do final da década de 90, com incremento a partir do século XXI. Estas ocorreram em diferentes contextos profissionais da gestão desportiva, designadamente, autarquias locais, clubes e federações desportivas, sendo que o instrumento de recolha de dados foi o questionário, exceptuando uma das pesquisas que complementou com entrevistas exploratórias (MAÇAS, 2006).

A pluralidade de amostras utilizadas evidencia o vasto leque de profissionais que operam no âmbito da gestão do desporto. Os estudos utilizaram amostras homogéneas, designadamente de gestores desportivos (VAZ, 2001; Costa, 2002; Nunes 2004) e diretores/dirigentes desportivos (Marcelino, 1997; DuARTe, 2004; MaÇÃs, 2006). O estudo que utilizou a amostra mais numerosa foi o de Costa (2002) no total de 174 gestores desportivos (71 com funções de chefia e 103 sem funções de chefia), enquanto que a amostra mais reduzida incorporou 19 gestores desportivos (VAZ, 2001).

As primeiras investigações portuguesas acerca do perfil de competências do gestor desportivo datam da década de 90 , seguindose um ligeiro incremento a partir do século XXI.

No que concerne à caracterização do perfil de competências do gestor desportivo, numa primeira fase, o planeamento foi a dimensão mais relevante (MARCELINO, 1997). Contudo, estudos mais recentes relevam outras valências tais como, organizar, comunicar, liderar, decidir e controlar que reclamam, fundamentalmente, a integração de quatro tipos de recursos: humanos, financeiros, físicos e informativos, (Duarte, 2004, Maças, 2006; Vaz, 2001).

Identificando o contexto específico do gestor desportivo a exercer atividade em municípios, os resultados encontrados evidenciaram destrinça entre os gestores municipais com funções de chefia e de não chefia (CostA, 2002). Nos primeiros destacam-se as atividades de concepção e de controlo (planeamento de novas ações e projetos, criação de novos modelos de intervenção e definição de linhas orientadoras das políticas de desenvolvimento desportivo da autarquia) e nos segundos relevam as funções de comunicação

Mevimento, Porto Alegre, v. 17, n. 01, p. 255-279, janeiro/março de 2011. 
e concepção. Ainda no que se refere ao desempenho dos gestores desportivos municipais com a especificidade de intervenção na construção dos espaços e infraestruturas desportivos outras funções são destacadas: gerir recursos humanos e atividades e desenvolver técnicas de marketing (NuNES, 2004).

Em consonância com Pires (1998), parece assim evidente que as competências necessárias a um bom desempenho do gestor municipal são de carácter diversificado porquanto englobam aspectos estratégicos, conceptuais, técnicos e interpessoais. As aptidões estratégicas baseiam-se na capacidade do gestor para definir uma linha de ação e alcançar os objectivos definidos pela organização, atendendo à respectiva missão e vocação. As aptidões conceptuais remetem para a capacidade do gestor entender a organização como um todo e a contribuição de cada uma das partes nos resultados globais. As aptidões técnicas consistem no modo como o gestor domina o conhecimento, metodologias e instrumentos específicos do seu trabalho. Por último, e não menos importante, as aptidões interpessoais correspondem a capacidade de comunicar e de se relacionar com as pessoas da organização, com o intuito de as compreender, motivar e dirigir para os objectivos finais.

2.1.3 OS GESTORES DESPORTIVOS NAS VARIANTES TERMINOLÓGICAS DE DIRETORES, ADMINISTRADORES E DIRIGENTES DESPORTIVOS: COMPETÊNCIAS E FUNÇÕES

A análise efectuada até ao momento das investigações nacionais e internacionais demonstra que, não obstante a similaridade das funções desenvolvidas por profissionais que laboram no âmbito da gestão desportiva, as terminologias utilizadas para os designar varia entre gestores, diretores, administradores e dirigentes desportivos. Parecenos que tal explicação se pode fundar no facto da área profissional da gestão desportiva ser recente e estar em franca expansão, não existindo ainda uma delimitação clara e conceptual da designação do respectivo profissional e do seu âmbito de intervenção (Costa; Claudino, 1995).

Inseridos nesta disparidade terminológica, invocando o perfil de competências funcionais de diretores, administradores e dirigentes

Movimento, Porto Alegre, v. 17, n. 01, p. 255-279, janeiro/março de 2011. 
desportivos podem ser mencionados os estudos de Hatfield, Wrenn e Bretting (1987); Olafson e Hastings (1988); Branch (1990); Judd (1990); Marcelino (1997); Danylchuck e Chelladurai (1999); White (2004); Duarte (2004) e Maçãs (2006).

As competências ao nível do marketing, da gestão financeira e das relações públicas são muito valorizadas pelos diretores desportivos, assim como, a extroversão, o saber comunicar, o julgar e considerar, a integração e a orientação superiores são também assinaladas como imprescindíveis para quem assume comportamentos de planeamento, liderança, e coordenação de equipas de trabalho (Hatfield; Wrenn; Bretting, 1987; Olafson; Hastings, 1988; Marcelino, 1997; MaÇas, 2006; Duarte, 2004).

Branch (1990) acresce referindo que os comportamentos de liderança não devem ser orientados unicamente para os resultados e realização de tarefas, mas também para as relações interpessoais com o intuito de obter uma maior eficácia organizacional.

Enfatizando a competência dos diretores no relacionamento com os recursos humanos e financeiros das respectivas organizações, Danylchuck e Chelladurai (1999), destacam como funções mais desenvolvidas e mais importantes as que respeitam à gestão dos orçamentos, instalações e pessoal para as diferentes modalidades e equipas; assim como, ao nível da resolução de assuntos relacionados com o pessoal técnico, nomeadamente, supervisão e avaliação de rendimento, gestão de conflitos e acompanhamento de questões da vida dos jogadores. Competências estas realçadas no estudo de Judd (1990) e Maçãs (2006).

Por conseguinte, é visível que independentemente da designação de administrador, diretor ou dirigente, o perfil de competências é similar ao já exposto para o perfil do gestor desportivo.

\section{Considerações Finals}

De acordo com os critérios de seleção determinados nesta revisão sistemática a tipologia dos estudos empíricos a nível inter-

Mevimento, Porto Alegre, v. 17, n. 01, p. 255-279, janeiro/março de 2011. 
nacional divide-se em artigos peer review e dissertações de doutoramento, enquanto que em Portugal são unicamente estudos académicos, designadamente, dissertações de mestrado e de doutoramento. $\mathrm{O}$ instrumento de recolha de dados recorrentemente utilizado foi o questionário.

Os estudos internacionais publicados em revistas peer review focam as competências de planeamento, de marketing, das relações públicas e dos processos de liderança e de tomada de decisão como as mais importantes do gestor desportivo. Por sua vez, os estudos académicos realçam o conhecimento na área do desporto, a comunicação e a gestão das relações pessoais. Os estudos académicos realizados em Portugal evidenciam o planeamento, a organização e gestão de eventos e a coordenação de equipas como as competências mais relevantes.

Genericamente, decorre destas investigações que as competências mais valorizadas são as de planeamento (atividades, projetos e eventos), de gestão de recursos (humanos, financeiros, instalações e equipamentos), de liderança, de marketing e de coordenação de equipas.

Parece também inquestionável que o planeamento é a função transversal comum aos diversos estudos. De sublinhar ainda que as competências e funções inerentes à gestão financeira, designadamente, a contabilidade e o orçamento, bem como a importância do comportamento ético foram evidenciadas, fundamentalmente, em alguns estudos internacionais.

De realçar ainda a heterogeneidade de designações para a atividade dos gestores desportivos, variando entre administradores, diretores e dirigentes. Contudo, as competências funcionais adstritas a estes profissionais espelham um espectro similar, sendo que as dissemelhanças podem advir dos contextos específicos de intervenção (educativo, municipal, associativo e empresarial).

Por fim, tendo em consideração a natureza das pesquisas efectuadas, o tipo de instrumentos utilizados e ainda a variabilidade de contextos profissionais estudados, parece recomendável avançar para

Movimesto, Porto Alegre, v. 17, n. 01, p. 255-279, janeiro/março de 2011. 
estudos de natureza mais qualitativa que transponham o paradigma positivista. Dever-se-á atender também em futuros estudos às categorias organizacionais das dimensões "pública e privada", porquanto podem influenciar o comportamento dos gestores, muito em razão dos respectivos regimes políticos de governação. Adicionalmente, importará também investigar in locus o modo como a competência se manifesta na ação, por conseguinte importa equacionar a triangulação de dados, recorrendo a diferentes instrumentos (e.g. entrevistas, questionários, observação participada e não participada), e a diferentes metodologias (e. g. etnografia, narrativas, focus group).

Movimento, Porto Alegre, v. 17, n. 01, p. 255-279, janeiro/março de 2011. 
Systematic review on the competencies profile of the sport managers

Abstract: This study is a systematic review of the literature on the sports manager focused on the competencies and tasks. The research used electronic databases (1980-2009), and masters and PhD dissertations of Portuguese Public Universities. The key words used were 'sport manager', 'sport directors', 'sport-managers and organization', 'competence and sport managers', 'sport director and organizational', 'responsibilities and sport managers'. 15 out of the 30 studies were peer review papers and 15 were masters and $\mathrm{PhD}$ dissertations.

The competencies and tasks more valued were: planning, management of resources, leadership, marketing, control and coordination of teams. Planning was the cross-sectional competence.

Keywords: Management. Sports: organization \& administration. Review Literature as Topic

Una revisión sistemática sobre el perfil de competencias del gerente deportivo

Resumen: Este estudio fue una revisión sistemática de la literatura, se centró en las competencias y tareas del gerente de deportes. La investigación fue realizada en bases de datos electrónicas (1980-2009), y másteres y doctorales tesis de las Universidades Públicas de Portugal. Las palabras clave utilizadas fueron "sport manager", "sport directors", "sport manager and organization", "competency and sport manager", "sport director and organizational", "responsibilities and sport managers". Resultaran 30 estudios, 15 artículos revisados por pares y 15 disertaciones. Las competencias y funciones más valoradas fueron: planificación, gestión de recursos, liderazgo, marketing, control y coordinación de equipos. La planificación fue la competencia transversal.

Palabras clave: Gerencia. Deportes: organización \& administración .Literatura de Revisión como Asunto.

\section{REFERÊNCIAS}

BARCELONA, Bob; ROSS, Craig. An analysis of the perceived competencies of recreational sport administrators. Journal of Park and Recreation Administration, Urbana, v. 22, n. 4, p. 25-42, 2004.

Novimento, Porto Alegre, v. 17, n. 01, p. 255-279, janeiro/março de 2011. 
BARCELONA, Robert. An analysis of the perceived competencies of recreational sport managers: Toward a Competency-based Model for Academic and Professional Development. 2001. 204 f. Dissertation (PhD in Philosophy) - School of Health, Physical Education and Recreation, Indiana University, Bloomington, 2001.

BASTOS, Flávia. Perfil do administrador esportivo de clubes sócio-culturais e esportivos de São Paulo/Brasil. Revista Mackenzie de Educação Física e Esporte, São Paulo, v. 1, n. 5, p. 13-22, 2006.

BRANCH, Dallas. Athetic director leader behavior as predictor of Intercollegiate Athetic Organizational effectiveness. Journal Sport Management, Champaign, n. 3, p. 158-164, 1990 .

CARROLL, William. Historial precedents for and perceived competencies of sports administrators regarding legal implications of sports administration. 1994. 307 f. Dissertação (Mestrado em Educação) - Daphne: United States Sport Academy, 1994.

CHELLADURAI, Packianathan. Gestão do Desporto: definir a Área. Ludens, Lisboa, v.15, n.4, p.67-71, out./dez.1995.

CHENG, Chih-Fu. Competency assessment in sport management for the Republic of China. 1993. 151 f. Dissertação (Mestrado em Educação) - Greeley: College of Health and Human Sciences School of Kinesiology and Physical Education, University of Northern Colorado, 1993.

CHEN, Chih-Vi. An examination of the competencies needed by sport managers in Taiwan. 2004. 311 f. Dissertação (Mestrado em Filosofia) - Idaho: College of Graduate Studies University of Idaho, 2004.

COSTA, Carla; CLAUDINO, Rui. Gestão de recursos humanos: competências e currículos em gestão desportiva - perspectivas. Lisboa: Faculdade de Motricidade Humana, Universidade Técnica de Lisboa, 1995.

COSTA, Pedro Xisto. Conteúdo funcional do gestor de desporto municipal. 2002. 179 f. Mestrado (Gestão do Desporto). Lisboa: Universidade Técnica de Lisboa, Faculdade de Motricidade Humana. 2002.

CUSKELLY, Graham; AULD, Christopher. Perceived importance of selected Job responsibilities of sport and recreation managers: An Australian Perspective. Journal Sport Management, Champaign, n. 5, p. 34-46, 1991.

DANYLCHUK, Karen; CHELLADURAI, Packianathan. The nature of managerial work in Canadian Intercollegiate Athletics. Journal of Sport Management, Champaign, n. 15, p. 364-379, 1999.

DUARTE, Joaquim. Perfil funcional do dirigente desportivo: estudo efectuado em escalões de formação na modalidade de futebol no distrito de Setúbal. 2004. 249 f. Dissertação (Mestrado). Lisboa: Faculdade de Motricidade Humana, Lisboa, 2004.

Mevimento, Porto Alegre, v. 17, n. 01, p. 255-279, janeiro/março de 2011. 
ELLARD, James. A competency analysis of managers of commercial recreational sport enterprises. 1984. 217 f. Dissertação (Mestrado em Recreação). Bloomington:School of Health, Physical Education and Recreation, Indiana University, 1984

HATFIELD, Brad; WRENN, Jerry; BRETTING, Michael. Comparison of the Job responsibilities of Intercollegiate Sport General Managers. Journal os Sport Management, Champaign, n. 1, p. $129-145,1987$.

HORCH, Heinz-Dieter; SCHÜTTE, Norbert. Competencies of sport managers in German sport clubs and sport federations. Managing Leisure, London, n. 8, p. 70-84, abr. 2003.

IZQUIERDO, António; CASTILLO, Jesús; SANCHO, Juan; ABELLA, Carlos. Los profesionales de la organización y gestión de actividade física y deporte en las instalaciones deportivas y entidades: características sócio-demográficas y formativas. Internacional Journal of Sport Science, Madrid, v. 3, n.8, Julho, 2007.

JAMIESON, Lynn. Competency-Based Approaches to sport Management. Journal of Sport Management, Champaign, n.1, p. 48-56, 1987.

JUDD, Michael. Recommended management competencies of directors of athletics. 1990. Dissertação (Mestrado) - Los Angeles : University of Southern California, , 1990.

KIM, Heung Sik. Sport management competencies for sport centers in the Republic of Korea. 1997. 131 f. Dissertação (Mestrado em Sport Management Education) - Daphne: United States Sport Academy, 1997.

KJEKDSEN, Erik. The manager's role in the development and maltenance of ethical behavior in the sport organization. Journal of Sport Management, Champaign, $n$. 2, p. 99-113, 1992.

LAMBRECHT, Keith. A Study of Curricular Preparation Needs for Sport Club Managers. Journal of Sport Management, Champaign, n. 5, p. 47-57, 1991.

LAMBRECHT, Keith. An Analysis of the competencies of sports and Athetic Club Managers. Journal of Sport Management, Champaign, n.1, p. 116-128, 1987.

MAÇÃS, Victor. O Director Desportivo nas Organizações do Futebol em Portugal. Caracterização da actividade dos gestores de desporto nos clubes de futebol profissional e não profissional. 2006. 495 f. Dissertação (Doutorado em Educação Física e Desporto). Vila Real : Universidade Trás-os-Montes e Alto Douro, 2006.

MARCELINO, João. O director técnico nacional: estudo do perfil de funções dos directores técnicos nacionais que trabalham no âmbito das federações desportivas. 1997. 84 f. Dissertação (Mestrado em Gestão do Desporto) - Lisboa: Universidade Técnica de Lisboa, Faculdade de Motricidade Humana, 1997.

NUNES, Júlio. Intervenção do gestor do desporto municipal na construção dos espaços e infra-estruturas. 2004. 187 f. Dissertação (Mestrado) - Universidade Técnica de Lisboa, Faculdade de Motricidade Humana, Lisboa, 2004

Wovimento, Porto Alegre, v. 17, n. 01, p. 255-279, janeiro/março de 2011. 
OLAFSON, Gordon; HASTINGS, Dennis. Personal style and administrative behavior in amateur sport organizations. Journal Sport Management, Champaign, n. 2, p. 26-39, 1988.

PASCUAL, Carlos; ROMO, Gabriel; GARCIA, Juan; JIMENEZ, Alvaro. Competencias professionales del licenciado en ciências de la actividad física y del deporte. Motricidad: Revista de Ciencias de la Actividad Física y del Deporte, Cáceres, n.15, 2006.

PIRES, Gustavo. Educação Física: Contexto e inovação. O Director Técnico Nacional. Estudo do Perfil das funções. In: CONGRESSO DE EDUCACCÃO FíSICA E CIÊNCIAS DO DESPORTO DOS PAÍSES DE LÍNGUA PORTUGUESA, 5., 1998. Actas do V Congresso de Educação Física e Ciências do Desporto dos Países de Língua Portuguesa, Porto: Faculdade Ciências de Educação Física e Desporto da Universidade do Porto, 1998. v.1, p. 219-229.

REGIER, Karen. Perceived importance and performance of competencies of recreational sport administrators in Canadian Colleges and Universities. 1988. Dissertação (Mestrado em Human Kinetics) - Windsor : University of Windsor, 1988.

TSAI, Chang-Ching. A comparative analysis of the competencies of collegiate recreational sports directors in the United States and the Republic of China. 1995. 121 f. Dissertação (Mestrado - Minnesota: University of Minnesota, 1995.

VAZ, Fernando. Caracterização global das piscinas cobertas da região de Trás-os Montes: funções/competências dos gestores. 200. $241 \mathrm{f}$. Dissertação (Mestrado em Desporto de Recreação e Lazer) - Porto: Universidade do Porto, Faculdade Ciências do Desporto de Educação Física, 2001.

WHITE, Nancy. Profiles, career paths and perceived Job competencies of female higher education recreation directors. 2004. 123 f. Dissertação (Mestrado em Philosophy Health, Physical Education and Recreation). Albuquerque: University of New Mexico, 2004 